Article

\title{
The Reliability and Validity of Wearable Inertial Sensors Coupled with the Microsoft Kinect to Measure Shoulder Range-of-Motion
}

\author{
Peter Beshara 1,2,3,*iD, Judy F. Chen ${ }^{1,2}$, Andrew C. Read ${ }^{1}$, Pierre Lagadec ${ }^{4}$, Tian Wang ${ }^{2,3}$ and \\ William Robert Walsh 2,3 (D) \\ 1 Department of Physiotherapy, Prince of Wales Hospital, Sydney, NSW 2031, Australia; \\ judyquick@gmail.com (J.F.C.); mail.andrewread@gmail.com (A.C.R.) \\ 2 Faculty of Medicine, Prince of Wales Clinical School, University of New South Wales, \\ Sydney, NSW 2031, Australia; t.wang@unsw.edu.au (T.W.); w.walsh@unsw.edu.au (W.R.W.) \\ 3 Surgical \& Orthopaedic Research Laboratories, Prince of Wales Hospital, Sydney, NSW 2301, Australia \\ 4 Vald Performance, Brisbane, QLD 4006, Australia; p.lagadec@valdperformance.com \\ * Correspondence: Peter.Beshara@health.nsw.gov.au
}

Received: 14 October 2020; Accepted: 15 December 2020; Published: 17 December 2020

\begin{abstract}
Background: Objective assessment of shoulder joint active range of motion (AROM) is critical to monitor patient progress after conservative or surgical intervention. Advancements in miniature devices have led researchers to validate inertial sensors to capture human movement. This study investigated the construct validity as well as intra- and inter-rater reliability of active shoulder mobility measurements using a coupled system of inertial sensors and the Microsoft Kinect (HumanTrak). Methods: 50 healthy participants with no history of shoulder pathology were tested bilaterally for fixed and free ROM: (1) shoulder flexion, and (2) abduction using HumanTrak and goniometry. The repeat testing of the standardised protocol was completed after seven days by two physiotherapists. Results: All HumanTrak shoulder movements demonstrated adequate reliability (intra-class correlation (ICC) $\geq 0.70$ ). HumanTrak demonstrated higher intra-rater reliability (ICCs: 0.93 and 0.85 ) than goniometry (ICCs: 0.75 and 0.53 ) for measuring free shoulder flexion and abduction AROM, respectively. Similarly, HumanTrak demonstrated higher intra-rater reliability (ICCs: 0.81 and 0.94) than goniometry (ICCs: 0.70 and 0.93) for fixed flexion and abduction AROM, respectively. Construct validity between HumanTrak and goniometry was adequate except for free abduction. The differences between raters were predominately acceptable and below $\pm 10^{\circ}$. Conclusions: These results indicated that the HumanTrak system is an objective, valid and reliable way to assess and track shoulder ROM.
\end{abstract}

Keywords: shoulder; range of motion; sensor; Kinect; goniometry; measurement

\section{Introduction}

Measuring the active range of motion (AROM) of the shoulder joint is a fundamental component in any physical examination to diagnose disease, identify functional limitations and monitor patient progress after conservative therapy or surgical intervention [1,2]. Therefore, reproducible measurements of AROM using valid and reliable tools are essential to objectively assess outcomes for individuals with shoulder dysfunction.

Universal goniometry (UG) is the most widely used instrument to measure the range of motion (ROM) of body joints in clinical settings [3,4]. It consists of two transparent arms connected to a circular protractor with scales between 0 and 360 degrees. The centre of the UG is aligned with the centre of the joint, with one arm aligned to the stationary limb and the other arm aligned with the moving 
limb. The literature recognises UG as a "gold-standard" due to its low cost and portability in clinical settings [5-7]. Studies have established modest-excellent intra-rater reliability for UG measurements with intra-class correlations (ICCs) ranging from 0.58 to 0.99 for active abduction [8-11] and from 0.53 to 0.96 for active shoulder flexion [9-11]. However, UG engenders a low inter-rater reliability [1] and requires both hands, thereby reducing the ability to stabilise the joint [12]. Furthermore, UG accuracy is dependent upon clinician skills and experience [13].

The recent development of small, portable, and wearable electromechanical sensors can bridge the gap between the practicality of commonly used clinical tools and more accurate, yet expensive, optical systems. Inertial motion units (IMUs) comprise 3-axis accelerometers, 3-axis magnetometers and 3-axis gyroscopes. IMUs, when paired with data fusion software, can define motion, heading and orientation [14]. The accuracy of wearable IMUs has improved over time with several studies validating its use for joint angle measurement [15-20].

Picerno et al. [21] reported excellent intra-rater reliability (ICC $=0.955,95 \%$ confidence interval $(C I)=0.930-0.979)$ when using a single IMU in 45 healthy subjects and good inter-rater reliability for shoulder flexion (ICC $=0.88$ ) and abduction (ICC $=0.88$ ) in healthy subjects $[21,22]$.

However, one limitation of IMUs is its potential to underestimate large-angle movements and overestimate small-angle movements [16].

The Microsoft Kinect (Microsoft Corp., Redmond, WA, USA) is a low-cost, marker-less system with a depth-sensing camera utilising infrared (IR) laser projection and an IR camera for real-time body tracking in three dimensions (3D). Developers have paired the device with software for the purpose of assessing and measuring human movement. The Kinect has been adapted and evaluated to assess 3-D shoulder kinematics during computer use [23], provide tactile feedback for stroke patients [24] and assess gait in children with cerebral palsy [25]. Several studies have validated the Kinect for the measurement of shoulder joint angles [26-32].

The Kinect, when compared against the gold-standard Vicon motion capture system for shoulder movements, has demonstrated higher levels of correlation and more acceptable levels of accuracy for forward flexion (Pearson's correlation $(r)=0.993$, the limits of agreement $(\mathrm{LoA}) \pm 11^{\circ}, 95 \% \mathrm{CI}$ : 8.7-12.6 $6^{\circ}$ ) and abduction $\left(r=0.991, \operatorname{LoA} \pm 11^{\circ}, 95 \%\right.$ CI: 8.7-12.8 $8^{\circ}$ [33]. Additionally, the Kinect has shown good-excellent levels of intra-rater reliability with ICCs between 0.85 and 0.99 for shoulder flexion and ICCs of 0.86-0.98 for abduction [29,30,34-36]. Similarly, studies have reported good-excellent levels of inter-rater reliability for Kinect measurements of shoulder flexion (ICCs: 0.89-0.97) and abduction (ICCs: 0.79-0.97) [36-38]. The characteristics and reliability values of the studies are summarised in Table 1.

Table 1. Summary of Kinect reliability studies.

\begin{tabular}{|c|c|c|c|c|c|}
\hline \multirow[b]{2}{*}{ Study } & \multirow[b]{2}{*}{ Target Population ( $n$ ) } & \multicolumn{2}{|c|}{ Intra-Rater Reliability ICC } & \multicolumn{2}{|c|}{ Inter-Rater Reliability ICC } \\
\hline & & $\begin{array}{l}\text { Shoulder } \\
\text { Flexion }\end{array}$ & $\begin{array}{l}\text { Shoulder } \\
\text { Abduction }\end{array}$ & $\begin{array}{l}\text { Shoulder } \\
\text { Flexion }\end{array}$ & $\begin{array}{l}\text { Shoulder } \\
\text { Abduction }\end{array}$ \\
\hline Hawi et al. & $\begin{array}{l}\text { Healthy, free ROM without deficits } \\
\qquad(n=7)\end{array}$ & 0.99 & 0.96 & - & - \\
\hline $\begin{array}{l}\text { Bonnechère } \\
\text { et al. }\end{array}$ & Healthy $(n=48)$ & - & 0.73 & - & - \\
\hline Çubukçu et al. & Healthy $(n=40)$ & 0.851 & 0.861 & - & - \\
\hline Hwang et al. & $\begin{array}{l}\text { Wheelchair usage for } 1 \text { year, able to sit } \\
\text { upright for at least } 4 \mathrm{~h} \text { a day, use a } \\
\text { wheelchair for }>40 \mathrm{~h} / \text { week }(n=8)\end{array}$ & $\begin{array}{l}\mathrm{L}=0.96 \\
\mathrm{R}=0.92\end{array}$ & $\begin{array}{l}\mathrm{L}=0.92 \\
\mathrm{R}=0.96\end{array}$ & - & - \\
\hline $\begin{array}{l}\text { Da Cunha Neto } \\
\text { et al. }\end{array}$ & Healthy $(n=10)$ & 0.97 & 0.98 & 0.91 & 0.97 \\
\hline Guneysu et al. & Healthy, children aged 3-11 $(n=8)$ & - & - & 0.8961 & 0.7935 \\
\hline Milgrom et al. & $\begin{array}{l}\text { Spinal cord injury, ability to self-propel } \\
\text { a manual wheelchair, wheelchair usage } \\
\text { for at least } 75 \% \text { of daily activities }(n=5)\end{array}$ & - & - & 0.97 & 0.94 \\
\hline
\end{tabular}


More recently, the integration of IMUs and the Kinect can potentially address the limitations of inertial sensor drift [39], noncalibration [40] and the Kinect's low sampling frequencies [41]. The sensor fusion provides better visualisation, greater precision and more accurate joint angle measurements [42-44].

The HumanTrak system (Vald Performance, Brisbane, Australia) is the coupling of inertial sensors with the updated Microsoft Kinect (v2). Prior studies have validated the Kinect (v2) for the assessment of postural control [41] and for upper limb functional assessment [45]. Mangal et al. [46] compared the Kinect (v2) and goniometry and reported a high correlation for ROM measurements with ICC values ranging between 0.95 and 0.98 .

HumanTrak has been validated against the Vicon motion capture system and AMTI force plate system with linear regression results demonstrating excellent correlation for shoulder flexion/extension (average \pm standard deviation (SD): $0.907 \pm 0.023$; minimum: 0.862; maximum: 0.9444) [47].

To our knowledge, no studies have investigated the coupling of inertial sensors with the Kinect to measure shoulder AROM or assess the accuracy of fixed target reaching. Furthermore, previous reliability and validity studies of either of the devices were statistically underpowered due to small sample sizes [27,48-50]. Previous systematic reviews have concluded more reliability studies are required to draw stronger conclusions [51-53].

Prior to coupled devices being used in clinical practice, they must be assessed for their measurement properties (i.e., reliability and validity). Therefore, this study was designed to determine the intraand inter-reliability of HumanTrak to measure active free and fixed shoulder motions. To establish construct validity, obtained results were compared with UG, which was chosen for its wide acceptance and applicability in clinical settings [54-57]. We hypothesised that the coupled system would possess adequate construct validity (ICC: $\geq 0.70, r:>0.75$ ) and reliability (ICC: $\geq 0.70$ ) for measuring free and fixed shoulder AROMs in healthy individuals.

\section{Materials and Methods}

The aims of the study were threefold: (1) to establish HumanTrak intra- and inter-rater reliability, (2) to determine HumanTrak's validity with goniometry, and (3) to compare HumanTrak results under two test conditions-free AROM and fixed AROM using consistent targets to reach.

\subsection{Participants}

Fifty asymptomatic adults (27 female and 23 male, mean age: 32.2, mean height: $171.4 \mathrm{~cm}$, left hand dominance: $(n=3))$ with no history of shoulder pathology were recruited from a public hospital in Sydney, Australia (Prince of Wales Hospital, Physiotherapy department). Participants from the hospital database were invited to participate via email. All participants gave their written informed consent before participation. The study was approved by the local hospital Ethics Committee (ref no. 17/005) and preregistered in the Australian New Zealand Clinical Registry (ACTRN12617000266369).

The sample size calculation was based on the data from a previous pilot study [58]. The calculation was conducted using the $G^{*}$ Power statistical tool to determine the sample size with 2 raters a significance level of 0.05 and a power of $95 \%$; a sample size of 50 participants would be required.

\subsection{Raters}

Rater A and Rater B were registered Physiotherapists with 10 years and 2 years of clinical experience, respectively. Both raters were responsible for body sensor placement, initiating the protocol instructions and executing the inertial motion system with the Kinect. Rater A was blinded to goniometric measurements between assessments with independent rater-recording results. HumanTrak data were automatically uploaded to a secure cloud-based server, and all ROM values were not visible to raters during or between assessments. The third independent unblinded rater collated and analysed all measurements. 


\subsection{Instruments}

\subsubsection{HumanTrak}

The HumanTrak system integrated four wireless inertial sensors (Figure 1A) worn on the wrists and ankles with an optical sensor (Kinect v2) to estimate human motions (Figure 1B). Optical and inertial data were processed and merged in real time to produce a full-body kinematic model of the subject.
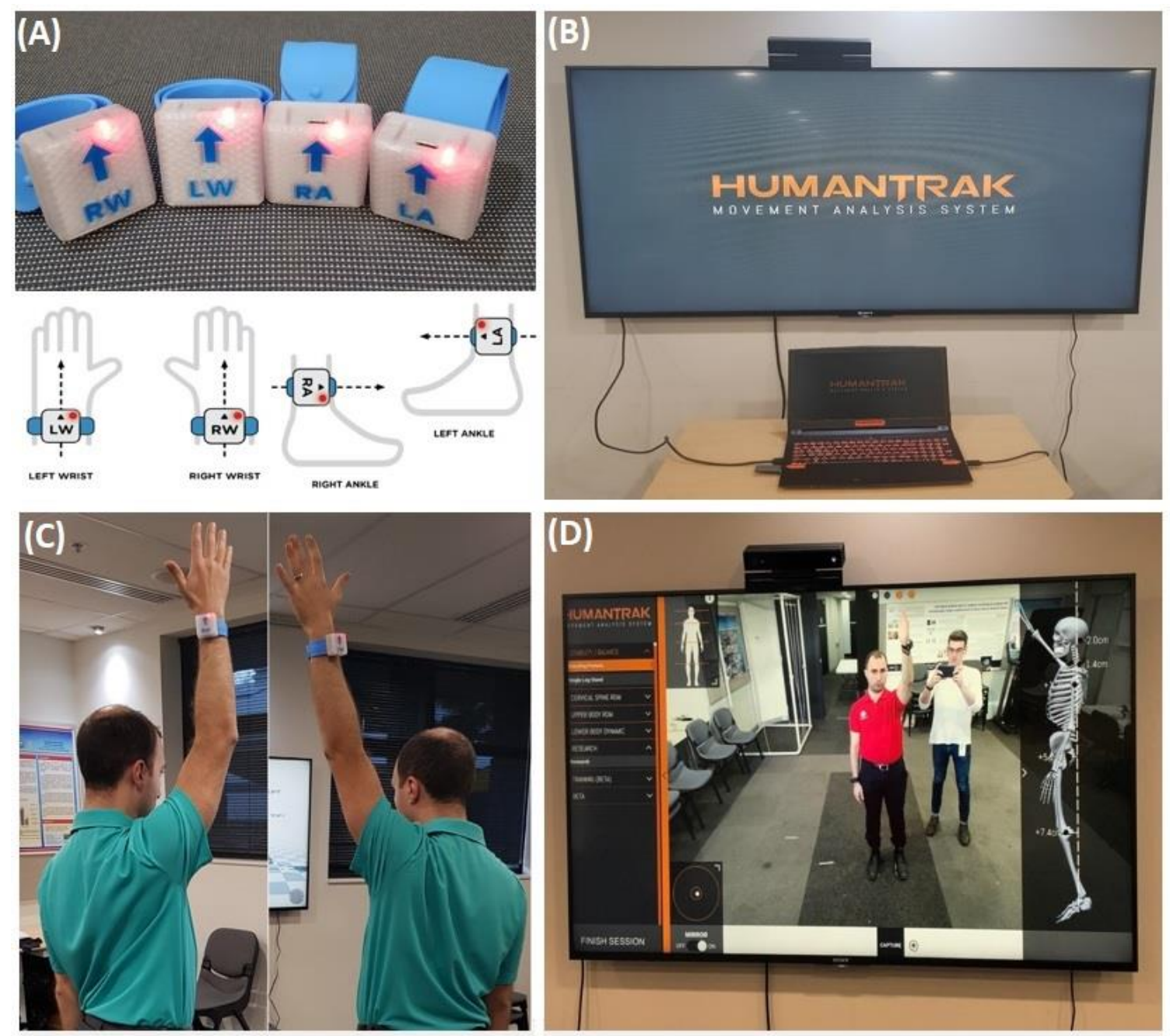

Figure 1. The HumanTrak system. (A) Inertial sensors. (B) Microsoft Kinect (v2) positioned above a television screen and connected to a laptop. (C) Shoulder-free active range of motion (AROM) demonstration. (D) HumanTrak interface.

The miniature inertial sensor (dimension: $23 \mathrm{~mm} \times 32.5 \mathrm{~mm} \times 7.6 \mathrm{~mm}$ ) consisted of a 3-axis gyroscope and a 3-axis accelerometer. Each sensor was applied bilaterally on the dorsal side of the wrist on the ulnar styloid and around the lower leg above the lateral malleolus. The sensor was securely attached to a plastic-covered slap bracelet with an interior metal coil spring.

A high-speed radio frequency $(\mathrm{RF})$ protocol transferred the inertial data to a receiving computer. The automatic calibration of the system was established, and the Kinect was positioned at a height of $1.4 \mathrm{~m}$ with a tilt of $-2.0^{\circ}$. Feet markers were placed $1.5 \mathrm{~m}$ away from the Kinect to ensure consistency with the participant placement. 


\subsubsection{Goniometer}

A single 12 inch plastic goniometer, model 12-1000 (BASELINE ${ }^{\circledR}$, Boise, ID, USA), was used by Rater A for all shoulder measurements.

\subsection{Procedures}

Bilateral shoulder measurements of forward flexion and abduction were performed in the standing position (Figure 1C). Instructions were verbally standardised, and participants were asked to move their arms "as far as possible" for free peak AROM. To assess fixed AROM, participants stood inside a PVC-constructed freestanding cage with coloured felt-tip-marked suspended ropes denoting the standardised position to reach in flexion and abduction (Figure 2). Targets were determined by the participant's height and comfort level. Identical targets were recorded and used by both raters on the second assessment. All shoulder movements were performed for three repetitions with a $3 \mathrm{~s}$ hold.

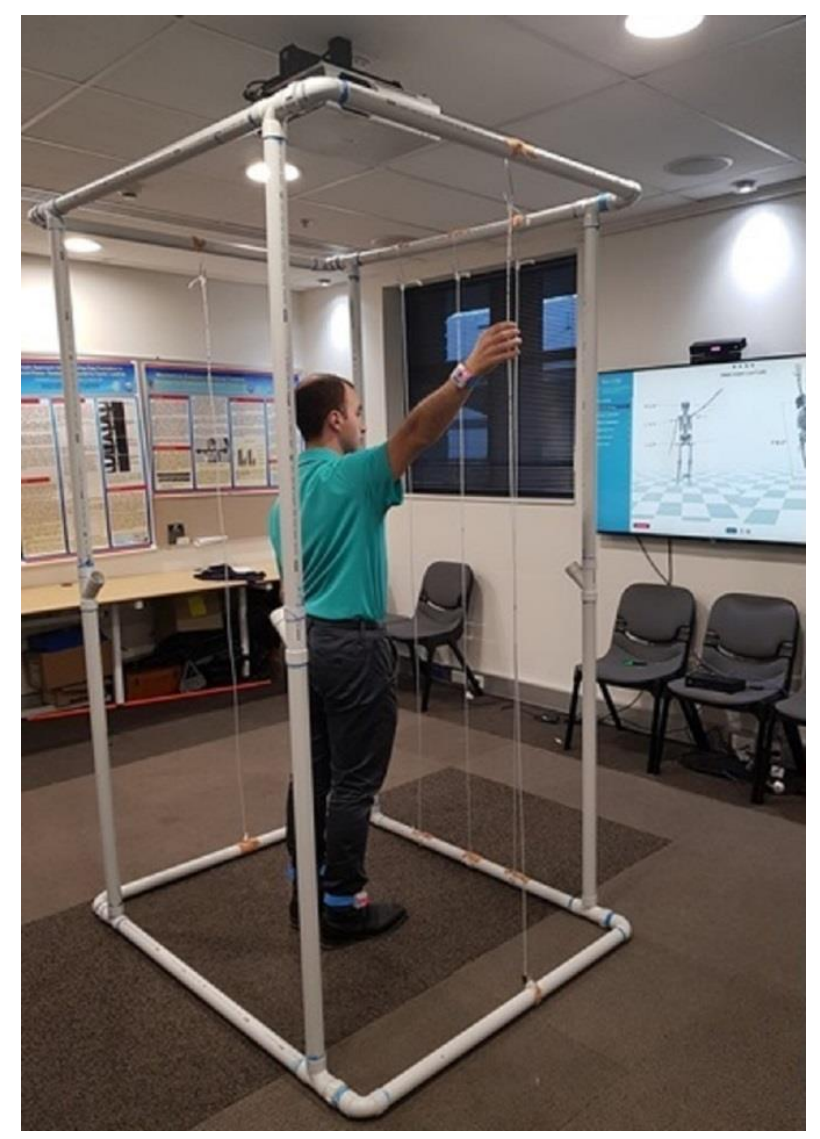

Figure 2. Fixed AROM with a freestanding cage.

Rater A assessed free peak AROM with a universal goniometer using the same protocol as that by Jain et al. [59]. The forward flexion angle was measured by placing the fulcrum of the goniometer on the middle of the glenoid fossa, one arm of the goniometer being aligned with the lateral epicondyle of the humerus and the other arm on a vertical line in the coronal plane (Figure $3 \mathrm{~A}$ ). The abduction angle was defined by placing the fulcrum of the goniometer in the middle of the posterior glenohumeral joint line, one arm of the goniometer being aligned with the lateral epicondyle of the humerus and the other arm on a vertical line in the sagittal plane (Figure 3B). 

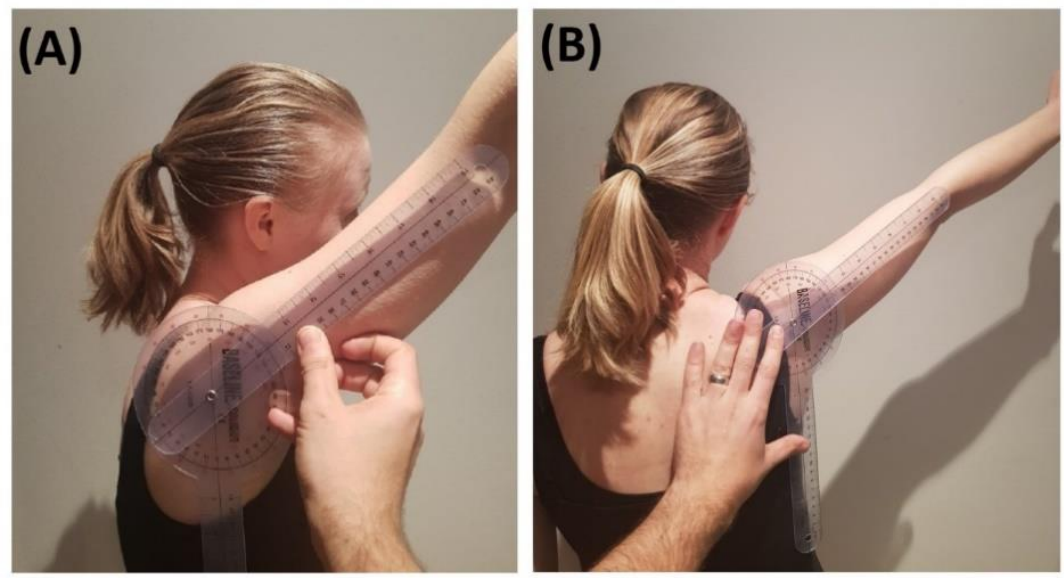

Figure 3. Goniometry measurement. (A) Forward flexion. (B) Abduction.

\subsection{Data Capture and Processing}

The HumanTrak software captured data in real time at $100 \mathrm{~Hz}$. The positional 3-D data of the kinematic model was postprocessed using a two-way Butterworth filter of order four to remove any residual noise, prior to calculating AROM values. Shoulder flexion/extension was calculated in the sagittal plane as the angle between the shoulder-elbow axis and the spine vertical axis (Figure 4A). Shoulder abduction/adduction was calculated in the coronal plane as the angle between the shoulder-elbow axis and the spine vertical axis (Figure 4B).
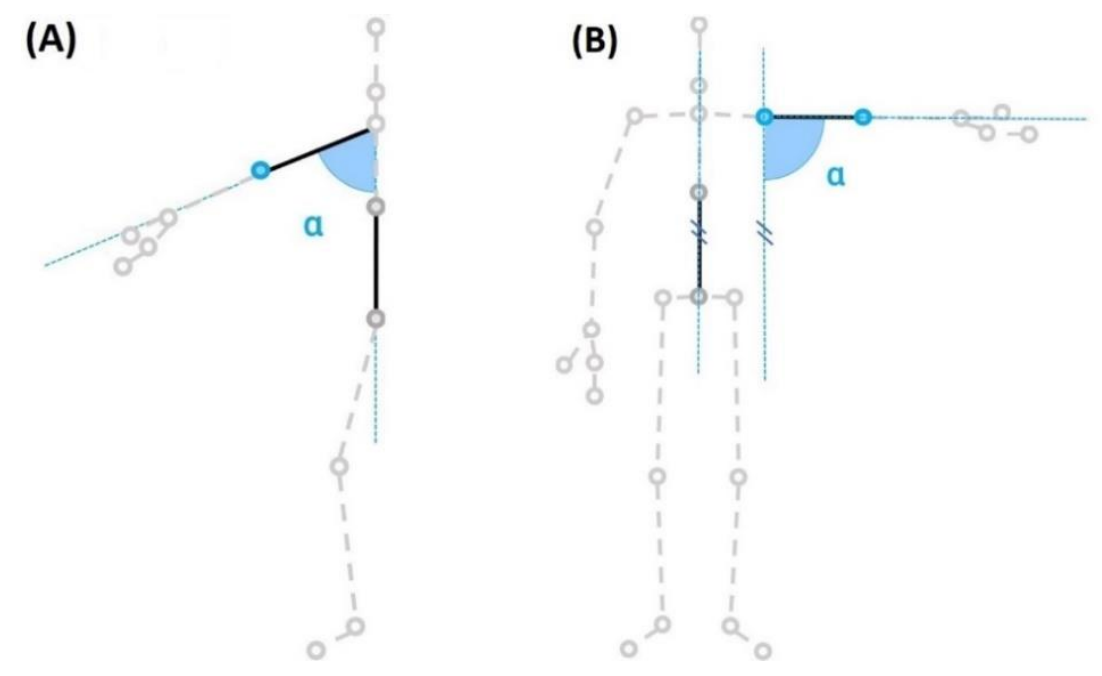

Figure 4. Shoulder joint range-of-motion (ROM) calculation with HumanTrak. (A) Shoulder forward flexion: angle $(\alpha)$ between the trunk (mid spine-spine base) and the upper limb (shoulder-elbow) in the sagittal plane. (B) Abduction: angle $(\alpha)$ between the trunk (mid spine-spine base) and the upper limb (shoulder-elbow) in the frontal plane.

\subsection{Statistical Analysis}

Data analysis was performed with SPSS version 24 for Windows. Descriptive data including mean measurement angles with SDs were calculated for Rater A's intra-rater analysis.

The reliability of all measurements was determined by ICC Model 3, 1 for the intra-rater component of analysis. This model was used, as the single rater was the only rater of interest. An (ICC) Model 2, $\mathrm{k}$ was used for the inter-rater analysis to determine if HumanTrak can be used with confidence and reliability among equally trained clinicians $[60,61]$. 
ICCs for absolute agreement were reported, and the mean value from each testing session was used for the analysis.

Given that ICCs may be affected by a limited range of data or intersubject variability, absolute measures of reliability were determined [62]. The standard error of measurement (SEM) was calculated using the equation: $\mathrm{SEM}=\mathrm{SD} \times \sqrt{1-\mathrm{ICC}}$. From the SEM, the minimal detectable change (MDC) was calculated using the formula MDC $=1.65 \times \mathrm{SEM} \times \sqrt{2}$ for test-retest data. This clinically meaningful degree of difference determines the magnitude of change that would exceed the threshold of measurement error [63]. Inter-rater reliability was visualised using Bland-Altman plots [64] with $95 \%$ limits of agreement (LoA) calculated using the formula: $95 \% \mathrm{LoA}=$ mean difference $\pm 2 \mathrm{SD}$. There is currently no agreed criterion in the literature for the acceptable levels of inter-observer agreement. Based on prior studies and clinical experience, any differences between raters greater than $\pm 5^{\circ}$ were considered clinically significant, and exceeding $\pm 10^{\circ}$ were considered unacceptable [65]. Construct validity was determined with an (ICC) Model 3, k, Bland-Altman plots, mean differences, 95\% LoA and Pearson's correlation to determine if both methods of measurement analysis produced comparable results. If the $95 \%$ LoA were greater than $\pm 5^{\circ}$, then the discrepancies between measurement systems were considered clinically significant $[27,64]$.

\subsection{Quality Criteria}

Reliability and construct validity were assessed using the criteria by Terwee et al. [66]. Reliability was considered adequate, if the tests ICC was $\geq 0.7$, with an ICC of $<0.7$ considered inadequate. For construct validity, a correlation of $\geq 0.75$ was considered adequate, and that of $<0.75$ was considered inadequate. These criteria have been validated in previous studies of measurement properties [67].

\section{Results}

\subsection{Intra-Rater Reliability}

The results of intra-rater reliability with ICC, SEM and MDC values are presented in Table 2. All free and fixed AROM HumanTrak shoulder movements demonstrated adequate reliability (ICC $\geq 0.7$ ).

Table 2. Intra-rater reliability and Pearson's $r$ (HumanTrak) of rater A $(n=50)$.

\begin{tabular}{ccccccc}
\hline Free AROM & Mean \pm SD $\left(^{\circ}\right)$ & ICC $_{\mathbf{3}, \mathbf{1}}$ & $\mathbf{9 5 \%} \mathbf{C I}$ & SEM $\left({ }^{\circ}\right)$ & MDC $\left({ }^{\circ}\right)$ & $\boldsymbol{r}$ \\
\hline Forward flexion & $169.7 \pm 8.4$ & 0.93 & $0.89-0.96$ & 2.2 & 6.1 & 0.89 \\
Abduction & $175.8 \pm 6.8$ & 0.85 & $0.77-0.90$ & 2.7 & 7.5 & 0.73 \\
\hline Fixed AROM & & & & & & \\
\hline Forward flexion & $134.8 \pm 8.2$ & 0.81 & $0.72-0.87$ & 3.6 & 10.0 & 0.69 \\
Abduction & $124.5 \pm 10.8$ & 0.94 & $0.91-0.96$ & 2.7 & 7.5 & 0.91 \\
\hline
\end{tabular}

$\mathrm{SD}$ = standard deviation; ICC = intra-class correlation coefficient; $\mathrm{CI}=$ confidence interval; SEM = standard error of measurement; $\mathrm{MDC}=$ minimal detectable change; $r$ = Pearson's correlation.

For free AROM, the highest intra-rater reliability was observed for forward flexion. For fixed AROM in the cage, the highest intra-rater reliability was observed for abduction. All SEM and MDC values were relatively low, indicating good absolute reliability.

Adequate correlations $(r \geq 0.75)$ between week 1 and week 2 for HumanTrak were demonstrated for free forward flexion and fixed abduction (Table 2).

Goniometric intra-rater reliability measurements are presented in Table 3. All fixed and free AROM movements demonstrated adequate intra-rater reliability with the exception of free abduction. 
Table 3. Intra-reliability and Pearson's $r$ (Goniometry) of rater A $(n=50)$.

\begin{tabular}{ccccccc}
\hline Free AROM & Mean $\pm \mathbf{S D}\left({ }^{\circ}\right)$ & ICC $_{\mathbf{3 , 1}}$ & $\mathbf{9 5 \%} \mathbf{C I}$ & $\mathbf{S E M}\left({ }^{\circ}\right)$ & MDC $\left({ }^{\circ}\right)$ & $\boldsymbol{r}$ \\
\hline Forward flexion & $168.5 \pm 10.3$ & 0.75 & $0.64-0.82$ & 5.2 & 14.4 & 0.75 \\
Abduction & $172.5 \pm 10.8$ & 0.53 & $0.38-0.66$ & 7.4 & 20.5 & 0.53 \\
\hline Fixed AROM & & & & & & \\
\hline Forward flexion & $132.5 \pm 9.2$ & 0.70 & $0.50-0.82$ & 5.0 & 13.9 & 0.58 \\
Abduction & $124.4 \pm 8.2$ & 0.93 & $0.88-0.96$ & 2.7 & 7.4 & 0.87 \\
\hline
\end{tabular}

$\mathrm{SD}=$ standard deviation; ICC $=$ intra-class correlation coefficient; $\mathrm{CI}=$ confidence interval; $\mathrm{SEM}=$ standard error of measurement; $\mathrm{MDC}=$ minimal detectable change; $r=$ Pearson's correlation.

\subsection{Inter-Rater Reliability}

The results of inter-rater reliability with ICC, SEM and MDC values are presented in Table 4. For free AROM, all movements demonstrated adequate inter-rater reliability (ICC > 0.70). For fixed AROM in the cage, adequate inter-rater reliability was only observed for abduction.

Table 4. HumanTrak Inter-rater reliability $(n=15)$.

\begin{tabular}{ccccc}
\hline Free AROM & ICC $_{2, \mathbf{k}}$ & $\mathbf{9 5 \%} \mathbf{C I}$ & $\mathbf{S E M}\left({ }^{\circ}\right)$ & $\mathbf{M D C}\left({ }^{\circ}\right)$ \\
\hline Forward flexion & 0.92 & $0.87-0.96$ & 2.0 & 5.6 \\
Abduction & 0.88 & $0.77-0.93$ & 1.5 & 4.3 \\
\hline Fixed AROM & $\mathbf{I C C}_{\mathbf{2}, \mathbf{k}}$ & $\mathbf{9 5 \%} \mathbf{C I}$ & $\mathbf{S E M}\left({ }^{\circ}\right)$ & $\mathbf{M D C}\left({ }^{\circ}\right)$ \\
\hline Forward flexion & 0.65 & $0.41-0.80$ & 4.6 & 12.7 \\
Abduction & 0.98 & $0.96-0.99$ & 1.9 & 5.1 \\
\hline
\end{tabular}

ICC = intra-class correlation coefficient; CI = confidence interval; SEM = standard error of measurement; $\mathrm{MDC}=$ minimal detectable change.

To analyse differences further, agreement was assessed using Bland-Altman plots (Figure 5). The mean differences between raters were $0.9^{\circ}$ (free forward flexion), $1.2^{\circ}$ (free abduction), $3.0^{\circ}$ (fixed forward flexion) and $0.4^{\circ}$ (fixed abduction).
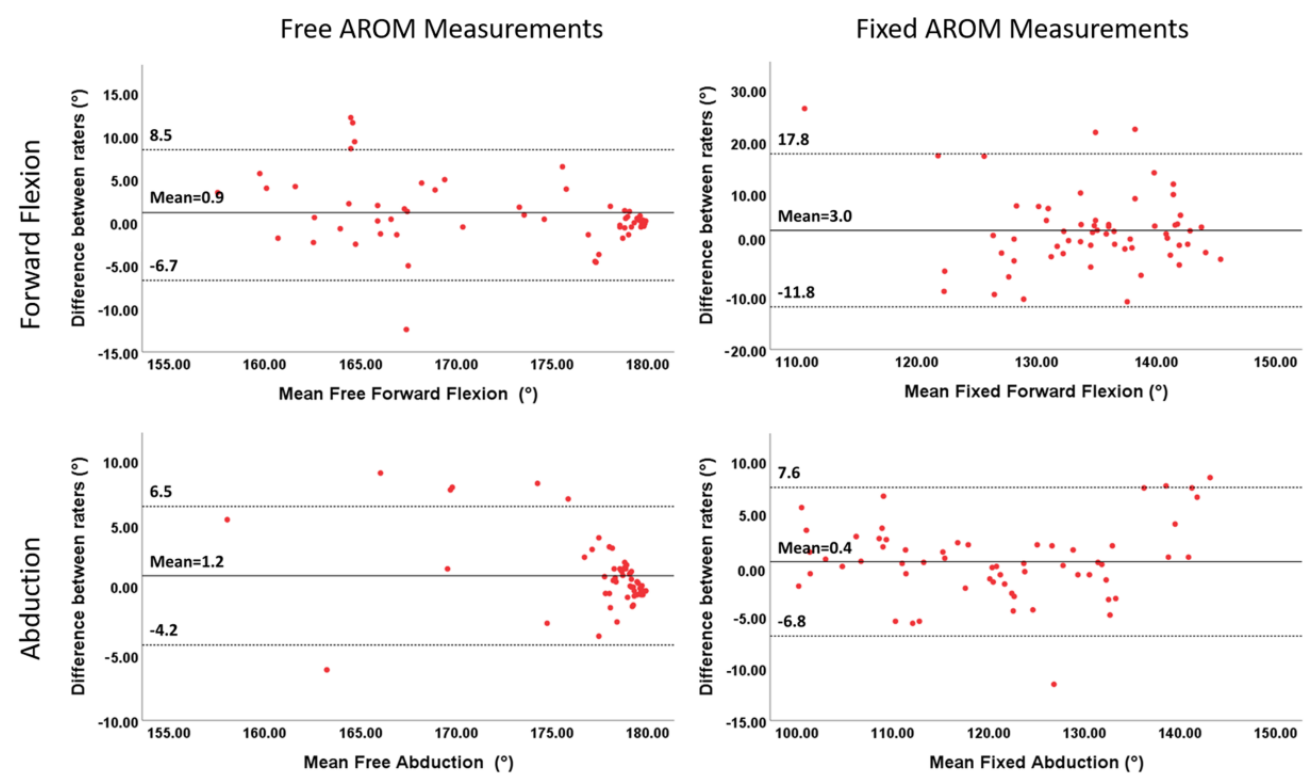

Figure 5. HumanTrak differences between raters for free and fixed forward flexion and abduction AROM. The solid black line is the mean difference between raters, and the segmented black lines show the $95 \%$ limits of agreements. 
The limits of agreement determined by the $95 \%$ CI were from $-6.7^{\circ}$ to $8.5^{\circ}$ for free forward flexion and from $-4.2^{\circ}$ to $6.5^{\circ}$ for free abduction. Fixed AROM differences varied between $-11.8^{\circ}$ and $17.8^{\circ}$ for forward flexion and between $-6.8^{\circ}$ and $7.6^{\circ}$ for abduction. For all movements, differences were predominately below $\pm 10^{\circ}$, and the majority of values did not exceed the clinically significant difference $\pm 5^{\circ}$.

\subsection{Construct Validity}

Table 5 shows the correlation between HumanTrak and UG. HumanTrak demonstrated adequate agreement only for free forward flexion. In contrast, the fixed AROM measurements demonstrated adequate correlations for both shoulder movements.

Table 5. Correlation between HumanTrak and goniometry $(n=50)$.

\begin{tabular}{cccccc}
\hline Free AROM & Mean \pm SD $\left(^{\circ}\right)$ & ICC & $\mathbf{9 5 \% ~ C I ~}$ & Mean diff $\left(^{\circ}\right)$ & $r$ \\
\hline Forward flexion & $169.4 \pm 9.5$ & 0.84 & $0.72-0.87$ & 2.05 & 0.77 \\
Abduction & $174.5 \pm 9.1$ & 0.59 & $0.60-0.82$ & 3.05 & 0.50 \\
\hline Fixed AROM & Mean \pm SD $\left(^{\circ}\right)$ & ICC & $\mathbf{9 5 \%}$ CI & Mean diff $\left(^{\circ}\right)$ & $r$ \\
\hline Forward flexion & $133.0 \pm 8.2$ & 0.98 & $0.97-0.99$ & 0.00 & 0.96 \\
Abduction & $124.3 \pm 9.4$ & 0.91 & $0.84-0.94$ & 2.18 & 0.87 \\
\hline
\end{tabular}

IC $\bar{C}=$ intra-class correlation coefficient; $\mathrm{CI}=$ confidence interval; diff = difference; $r$ = Pearson's correlation.

The $95 \%$ limits of agreement ranged between $-11.3^{\circ}$ and $15.4^{\circ}$ for free forward flexion, between -15.6 and $21.7^{\circ}$ for free abduction, between -4.8 and $4.8^{\circ}$ for fixed forward flexion and between -7.8 and $12.1^{\circ}$ for fixed abduction.

Furthermore, the points in the Bland-Altman plots for free forward flexion (Figure 6) and abduction (Figure 7) were uniformly and tightly scattered around the horizontal axis.

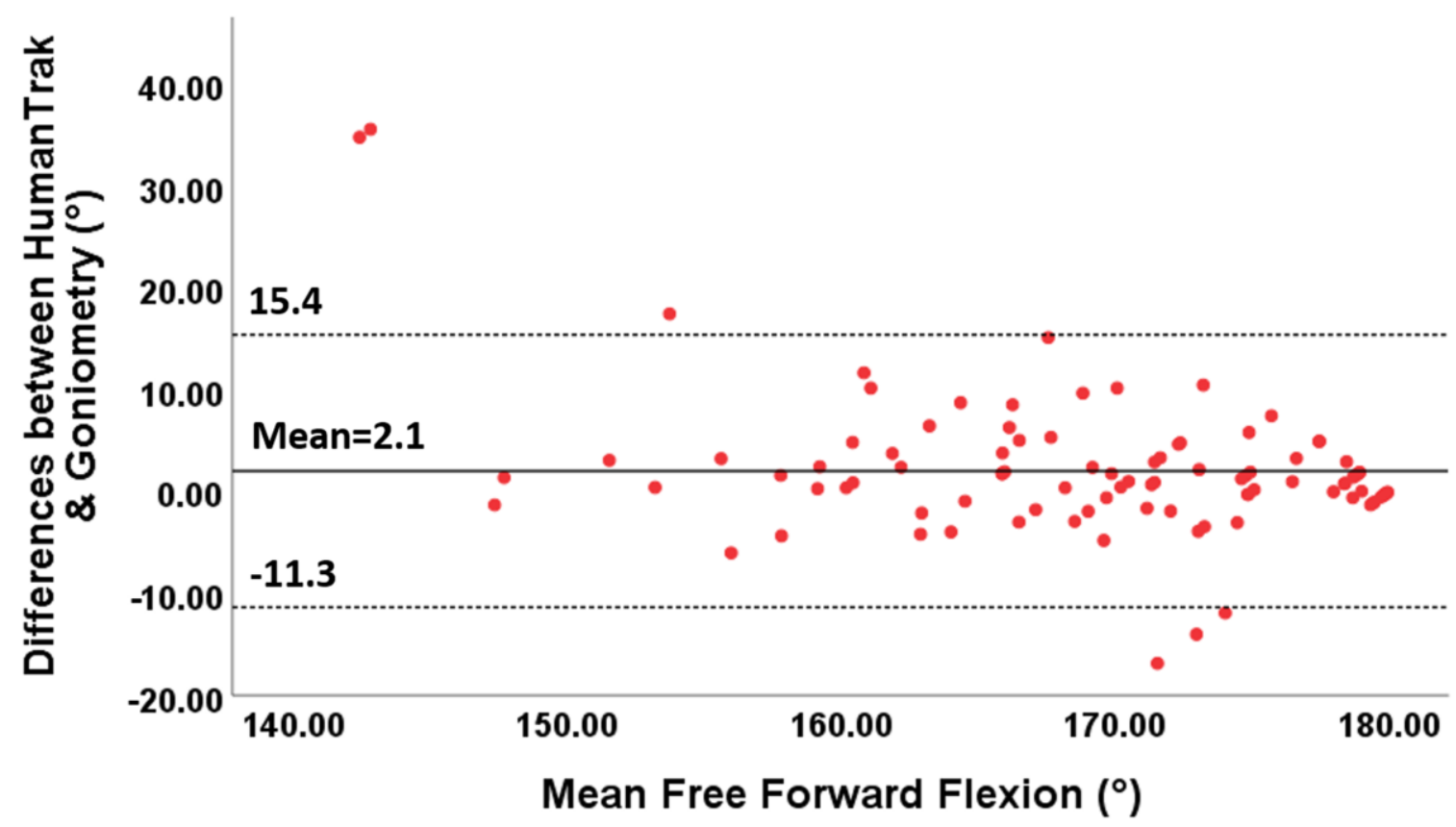

Figure 6. Bland-Altman plots for free forward flexion with limits of agreement. The differences between the two devices are plotted on the Y-axis, and the mean scores are plotted on the X-axis. 


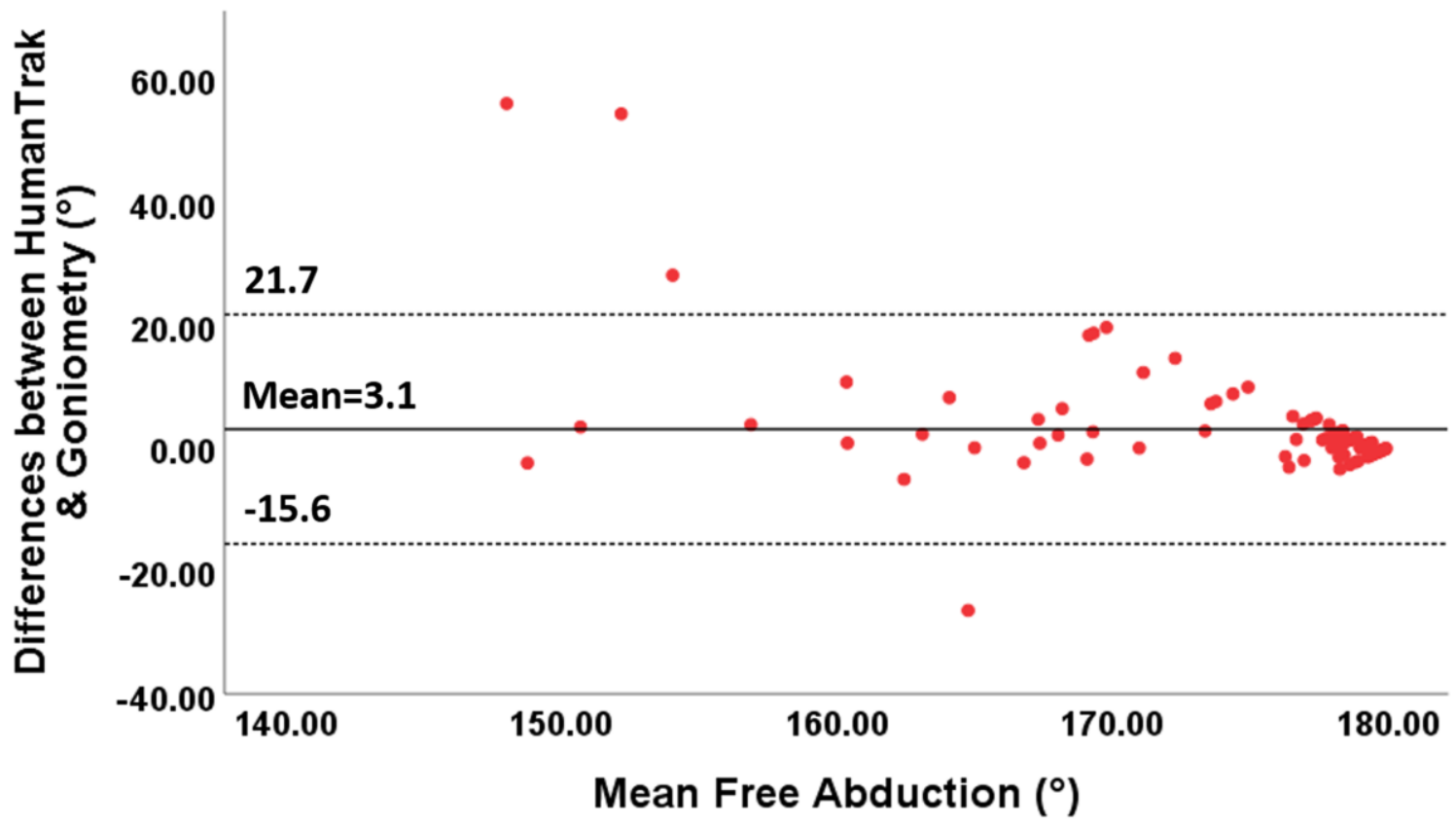

Figure 7. Bland-Altman plots for free abduction with limits of agreement. The differences between the two devices are plotted on the Y-axis, and the mean scores are plotted on the X-axis.

For fixed AROM, the points on the Bland-Altman plots demonstrated variability around the mean constant (Figures 8 and 9). Small mean differences between the two methods for forward flexion and abduction were demonstrated (Table 5).

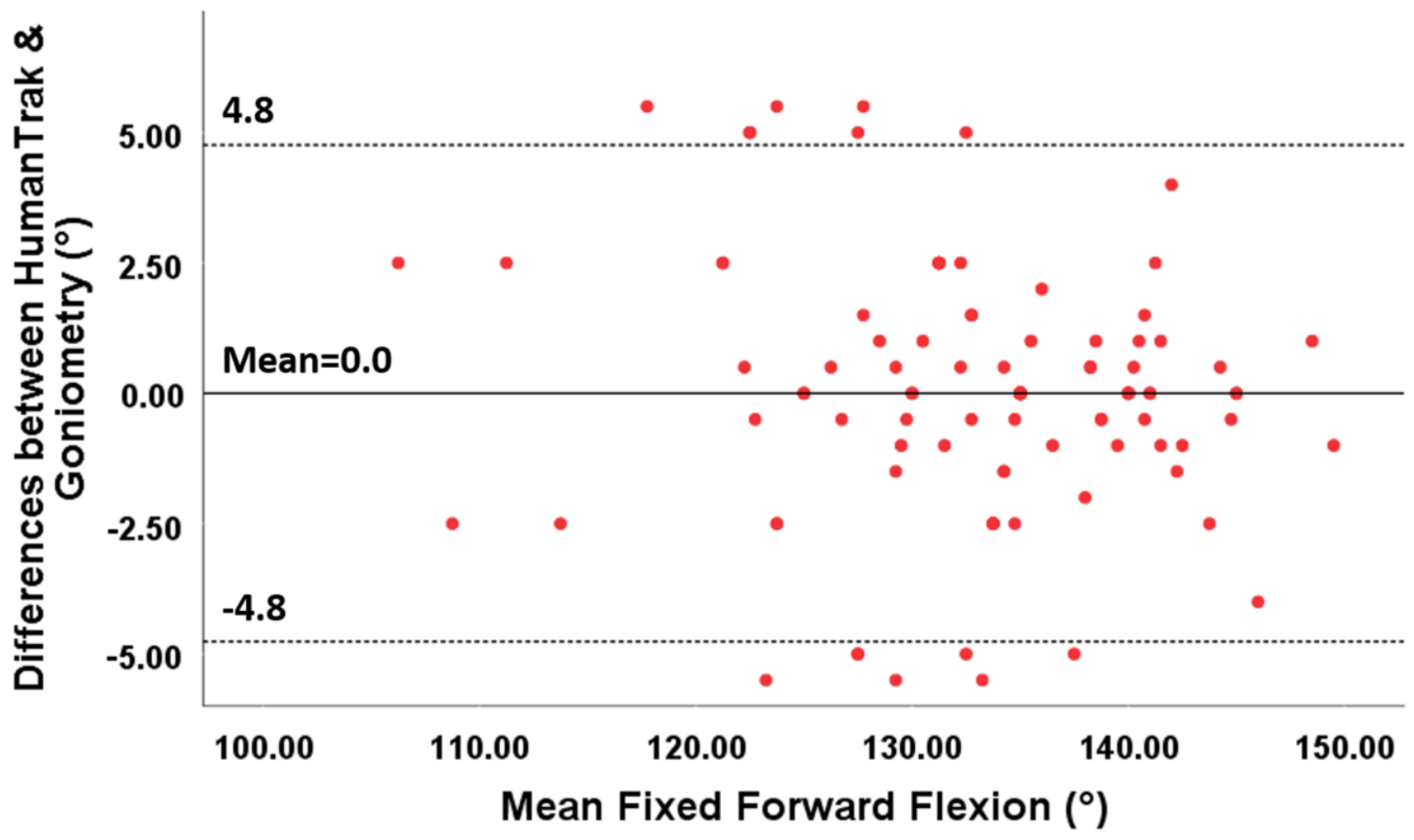

Figure 8. Bland-Altman plots for fixed forward flexion with limits of agreement. The differences between the two devices are plotted on the Y-axis, and the mean scores are plotted on the X-axis. 


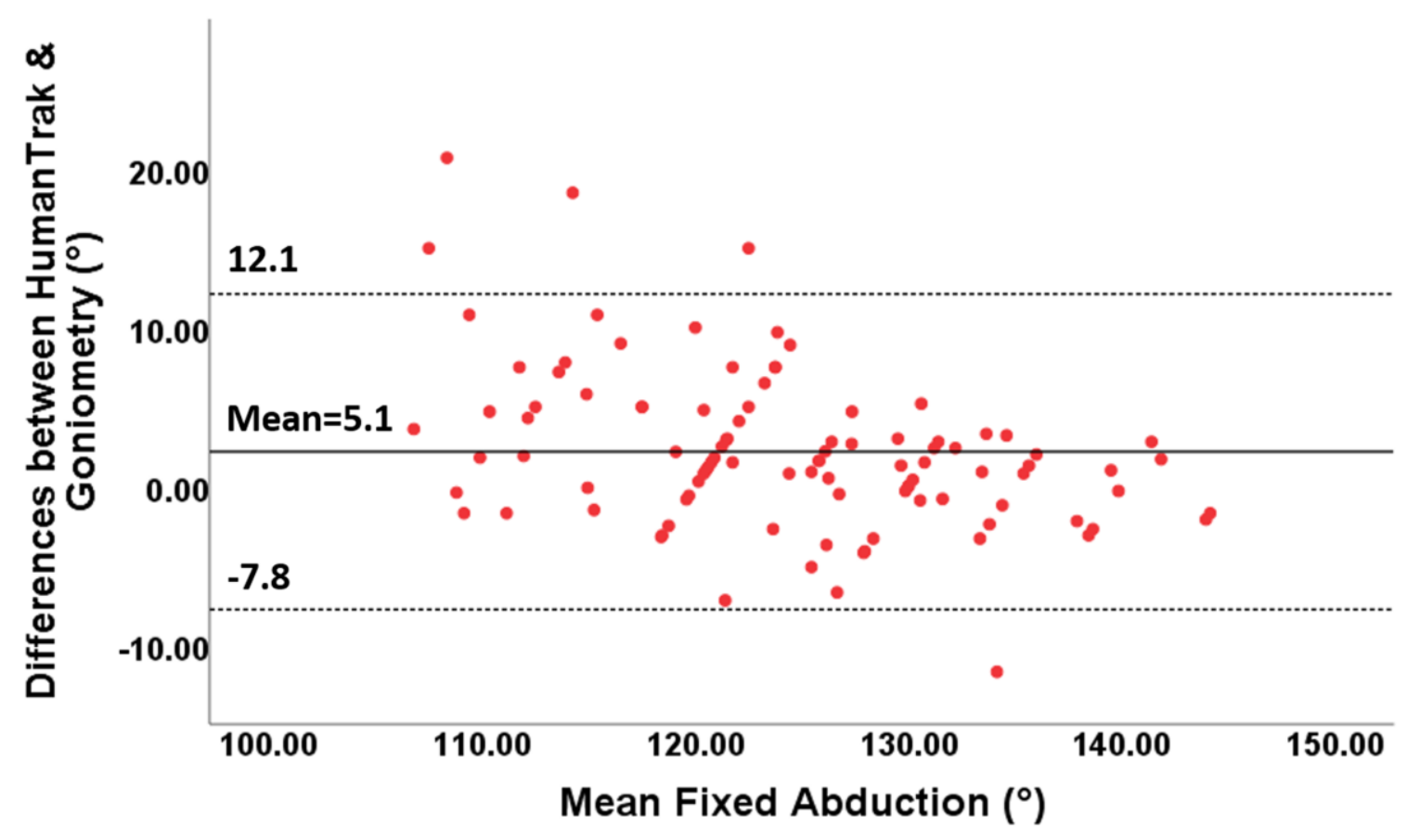

Figure 9. Bland-Altman plots for fixed abduction with limits of agreement. The differences between the two devices are plotted on the Y-axis, and the mean scores are plotted on the X-axis.

\section{Discussion}

Accurate and reliable measurements of shoulder mobility are important to diagnose pathological conditions, evaluate treatment effectiveness and monitor progress after surgery. This study demonstrates that a system using wearable inertial sensors coupled with the Microsoft Kinect is a reliable and valid way to measure active shoulder forward flexion and abduction.

The results confirmed the hypothesis that, under both test conditions, HumanTrak had higher intra-rater reliability for shoulder forward flexion (ICC $=0.93$ and 0.81) and abduction (ICC $=0.85$ and 0.94) than UG. HumanTrak demonstrated lower SEM and MDC values than goniometry with small measurement errors $\left(2-4^{\circ}\right)$, indicating good absolute reliability. Similar to our results, an initial study utilising the BioCap system (the beta version of HumanTrak) reported adequate intra-rater reliability for free shoulder forward flexion (ICC $=0.93$ and 0.83) and abduction (ICC $=0.82$ ) [58]. Previous studies have only investigated inertial sensors or the Kinect separately to measure shoulder joint angles. Using an electromagnetic tracking system (FASTRAK), Jordan et al. [68] achieved adequate intra-rater reliability for measuring active shoulder flexion (ICC $=0.74$ ). Huber et al. [27] reported excellent intra-rater reliability (ICCs: 0.76-0.98) with the Kinect in a small sample size of 10 healthy adults.

This study examined the inter-rater reliability of inertial sensors coupled with the Kinect. All free and fixed AROM movements demonstrated adequate inter-rater reliability (ICCs $=0.88-0.98$ ) with the exception of fixed forward flexion (ICC $=0.65$ ). The Bland-Altman plots demonstrated acceptable levels of agreement between raters, and the $95 \%$ LoA were below $\pm 10^{\circ}$ for all movements, except for fixed forward flexion. By constructing a freestanding cage with suspended ropes, we used a novel approach to assess HumanTrak's accuracy in detecting the same fixed point. Despite the best efforts to ensure the same targets were reached within and between trial sessions, human error from the participant cannot be discounted. Therefore, the higher SEM and MDC values for fixed forward flexion were likely due to experimental errors from participants not reaching the same target between raters.

This study established adequate reliability and construct validity between HumanTrak and goniometry only for free forward flexion (ICC $=0.84, r=0.77$ ). Similarly, Lee et al. [49] reported excellent agreement with the Kinect and goniometry for active shoulder flexion (ICC $=0.86$ ) and 
abduction $(I C C=0.93)$. Although authors reported higher ICC values, the study had a significantly smaller sample size of 15 healthy volunteers.

The Bland-Altman plots demonstrated low mean differences and wide 95\% LoA above the clinically significant threshold of $\pm 5^{\circ}$. For agreement, clinicians should recognise differences between HumanTrak and goniometry can be expected to vary by up to $\pm 15^{\circ}$. Compared to our results, Huber et al. [27] reported wider limits of agreement $\left(95 \%\right.$ LoA exceeding $\left.\pm 30^{\circ}\right)$ and significant levels of bias between the Kinect and goniometry for measuring active shoulder ROM. In contrast, Yoon et al. [48] reported acceptable validity between IMU and goniometry for shoulder angle measurements with the $95 \%$ LoA discrepancies between the measurements ranging within $\pm 5^{\circ}$. However, the sample size was small, participants were predominately women, and all shoulder movements were passive.

Experimental limitations may explain why the highest intra- and inter-rater reliability values were achieved for free forward flexion and fixed abduction. Participants performing free forward flexion without a target were more likely to consistently move their arm in the single sagittal plane. In contrast, it was observed that reaching forward for a target in the cage elicited substitute movements involving excessive shoulder abduction. It was observed that fixed abduction demonstrated higher reliability than free abduction. An explanation for this result is that unrestricted abduction can be performed in the scapular or coronal plane, resulting in a less consistent measurement. These findings highlight that regardless of HumanTrak's accuracy and reliability, careful positioning and rater observation are essential to avoid compensatory or unwanted movements.

We acknowledge this study had several limitations. First, we used goniometry as a "gold standard" rather than a motion capture system. Authors chose to not replicate findings that have previously validated HumanTrak against the Vicon system [47]. While the Vicon system is widely accepted as the gold standard for human motion analysis [69] and has demonstrated acceptable levels of accuracy when compared with the Kinect sensor for measuring shoulder ROM in healthy volunteers [18], it is an onerous and expensive system to implement in clinical settings.

Participants in this study were healthy, predominately young, and not stratified for age. However, this population was appropriate, since we eliminated functional deficits and pain as potential confounding variables to establishing reliability. For practical reasons, no attempts were made to measure participants at the same time of day on each occasion; hence, we did not control for any potential variations in AROM at different times of the day. Finally, caution should be used in interpreting the HumanTrak inter-rater reliability results due to the smaller sample size of 15 participants.

Current system limitations reside in the HumanTrak system calibration process where each subject is required to stand straight to allow adjustments for any tilt in camera orientation. Slight errors in tilt calibration can occur in cases where the participant is unable to completely stand straight. However, this can be avoided if a healthy participant is initially used for calibration prior to tracking the rest of the participants, since the tilt calibration is only camera-dependent and will not change between participants.

Shoulder AROM was calculated into specific planes: sagittal plane for flexion/extension and coronal plane for adduction/abduction. These planes are defined from the camera sensor's reference. As such, a current limitation is that the subject is required to perfectly face the camera to maximise the accuracy of the ROM measurements. Errors in measurement might occur, if the subject is facing the camera at an angle, with the amount of errors increasing as the angle increases.

\section{Conclusions}

HumanTrak is a reliable and valid tool for surgeons and physiotherapists to deliver a quick and functional evaluation of the shoulder. As a marker-less, nonintrusive system for ROM evaluation, HumanTrak demonstrates potential as feasible adjunct to clinical observation in rehabilitative and outpatient clinical settings. Inertial sensor technology coupled with optical-based systems can provide accurate and objective data to support clinical decision-making and facilitate better clinical outcomes. 
Author Contributions: Conceptualization, P.B., J.F.C. and W.R.W.; methodology, P.B., A.C.R. and T.W.; software, P.L.; validation, P.B., A.C.R. and T.W.; formal analysis, T.W.; investigation, P.B. and A.C.R.; resources, T.W., P.L. and W.R.W.; writing of review and editing, P.B., J.F.C. and W.R.W.; supervision, W.R.W. All authors have read and agreed to the published version of the manuscript.

Funding: This research received no external funding.

Acknowledgments: Authors would like to thank the staff of Prince of Wales Hospital who participated in this study.

Conflicts of Interest: P.L. is Head Biomechanist/Software Developer at Vald Performance.

\section{References}

1. Muir, S.W.; Corea, C.L.; Beaupre, L. Evaluating change in clinical status: Reliability and measures of agreement for the assessment of glenohumeral range of motion. N. Am. J. Sports Phys. Ther. NAJSPT 2010, 5, 98-110. [PubMed]

2. Terwee, C.; De Winter, A.F.; Scholten, R.J.; Jans, M.P.; Devillé, W.; Van Schaardenburg, D.; Bouter, L.M. Interobserver Reproducibility of the Visual Estimation of Range of Motion of the Shoulder. Arch. Phys. Med. Rehabil. 2005, 86, 1356-1361. [CrossRef] [PubMed]

3. Gajdosik, R.; Bohannon, R. Clinical measurement of range of motion: Review of goniometry emphasizing reliability and validity. Phys. Ther. 1987, 67, 1867-1872. [CrossRef] [PubMed]

4. Milanese, S.; Gordon, S.J.; Buettner, P.; Flavell, C.; Ruston, S.; Coe, D.; O'Sullivan, W.; McCormack, S. Reliability and concurrent validity of knee angle measurement: Smart phone app versus universal goniometer used by experienced and novice clinicians. Man. Ther. 2014, 19, 569-574. [CrossRef] [PubMed]

5. Brosseau, L.; Tousignant, M.; Budd, J.; Chartier, N.; Duciaume, L.; Plamondon, S.; O'Sullivan, J.P.; O'Donoghue, S.; Balmer, S. Intratester and intertester reliability and criterion validity of the parallelogram and universal goniometers for active knee flexion in healthy subjects. Physiother. Res. Int. 1997, 2, 150-166. [CrossRef] [PubMed]

6. Fieseler, G.; Laudner, K.G.; Irlenbusch, L.; Meyer, H.; Schulze, S.; Delank, K.-S.; Hermassi, S.; Bartels, T.; Schwesig, R. Inter- and intrarater reliability of goniometry and hand held dynamometry for patients with subacromial impingement syndrome. J. Exerc. Rehabil. 2017, 13, 704-710. [CrossRef] [PubMed]

7. Lau, T.; Lin, S.; True, T.; Wu, W.; McKivigan, J.M. Reliability and Validity of a Smartphone-Based Inclinometer Application Measuring Shoulder Internal Rotation. J. Phys. Fit. Med. Treat. Sports 2020, 7, e555725. [CrossRef]

8. Hayes, K.; Walton, J.R.; Szomor, Z.L.; Murrell, G.A. Reliability of five methods for assessing shoulder range of motion. Aust. J. Physiother. 2001, 47, 289-294. [CrossRef]

9. Kolber, M.J.; Hanney, W.J. The reliability and concurrent validity of shoulder mobility measurements using a digital inclinometer and goniometer: A technical report. Int. J. Sports Phys. Ther. 2012, 7, 306-313.

10. Greene, B.L.; Wolf, S.L. Upper extremity joint movement: Comparison of two measurement devices. Arch. Phys. Med. Rehabil. 1989, 70, 288-290.

11. Sabari, J.S.; Maltzev, I.; Lubarsky, D.; Liszkay, E.; Homel, P. Goniometric assessment of shoulder range of motion: Comparison of testing in supine and sitting positions. Arch. Phys. Med. Rehabil. 1998, 79, 647-651. [CrossRef]

12. Lea, R.D.; Gerhardt, J.J. Range-of-motion measurements. J. Bone Joint Surg. Am. 1995, 77, 784-798. [CrossRef] [PubMed]

13. Akizuki, K.; Yamaguchi, K.; Morita, Y.; Ohashi, Y. The effect of proficiency level on measurement error of range of motion. J. Phys. Ther. Sci. 2016, 28, 2644-2651. [CrossRef]

14. Zhang, Z.; Ji, L.; Huang, Z.; Wu, J. Adaptive Information Fusion for Human Upper Limb Movement Estimation. IEEE Trans. Syst. Man Cybern. Part A Syst. Hum. 2012, 42, 1100-1108. [CrossRef]

15. Teufl, W.; Miezal, M.; Taetz, B.; Fröhlich, M.; Bleser, G. Validity of inertial sensor based 3D joint kinematics of static and dynamic sport and physiotherapy specific movements. PLoS ONE 2019, 14, e0213064. [CrossRef] [PubMed]

16. Morrow, M.M.; Lowndes, B.R.; Fortune, E.; Kaufman, K.R.; Hallbeck, M.S. Validation of Inertial Measurement Units for Upper Body Kinematics. J. Appl. Biomech. 2017, 33, 227-232. [CrossRef] [PubMed]

17. Schall, M.C., Jr.; Fethke, N.B.; Chen, H.; Oyama, S.; Douphrate, D.I. Accuracy and repeatability of an inertial. measurement unit system for field-based occupational studies. Ergonomics 2016, 59, 591-602. [CrossRef] 
18. Zhou, H.; Stone, T.; Hu, H.; Harris, N. Use of multiple wearable inertial sensors in upper limb motion tracking. Med. Eng. Phys. 2008, 30, 123-133. [CrossRef]

19. Cutti, A.G.; Giovanardi, A.; Rocchi, L.; Davalli, A.; Sacchetti, R. Ambulatory measurement of shoulder and elbow kinematics through inertial and magnetic sensors. Med. Biol. Eng. Comput. 2008, 46, 169-178. [CrossRef]

20. El-Gohary, M.; McNames, J. Shoulder and Elbow Joint Angle Tracking With Inertial Sensors. IEEE Trans. Biomed. Eng. 2012, 59, 2635-2641. [CrossRef]

21. Picerno, P.; Viero, V.; Donati, M.; Triossi, T.; Tancredi, V.; Melchiorri, G. Ambulatory assessment of shoulder abduction strength curve using a single wearable inertial sensor. J. Rehabil. Res. Dev. 2015, 52, 171-180. [CrossRef] [PubMed]

22. Rigoni, M.; Gill, S.; Babazadeh, S.; Elsewaisy, O.; Gillies, H.; Nguyen, N.; Pathirana, P.N.; Page, R. Assessment of Shoulder Range of Motion Using a Wireless Inertial Motion Capture Device-A Validation Study. Sensors 2019, 19, 1781. [CrossRef] [PubMed]

23. Xu, X.; Robertson, M.; Chen, K.B.; Lin, J.-H.; McGorry, R.W. Using the Microsoft Kinect ${ }^{\mathrm{TM}}$ to assess 3-D shoulder kinematics during computer use. Appl. Ergon. 2017, 65, 418-423. [CrossRef] [PubMed]

24. Orand, A.; Aksoy, E.E.; Miyasaka, H.; Levy, C.W.; Zhang, X.; Menon, C. Bilateral Tactile Feedback-Enabled Training for Stroke Survivors Using Microsoft KinectTM. Sensors 2019, 19, 3474. [CrossRef]

25. Ma, Y.; Mithraratne, K.; Wilson, N.C.; Wang, X.; Ma, Y.; Zhang, Y. The Validity and Reliability of a Kinect v2-Based Gait Analysis System for Children with Cerebral Palsy. Sensors 2019, 19, 1660. [CrossRef]

26. Fern'Ndez-Baena, A.; Susin, A.; Lligadas, X. Biomechanical Validation of Upper-Body and Lower-Body Joint Movements of Kinect Motion Capture Data for Rehabilitation Treatments. In Proceedings of the 2012 Fourth International Conference on Intelligent Networking and Collaborative Systems, Bucharest, Romania, 19-21 September 2012; pp. 656-661.

27. Huber, M.E.; Seitz, A.; Leeser, M.; Sternad, D. Validity and reliability of Kinect skeleton for measuring shoulder joint angles: A feasibility study. Physiotherapy 2015, 101, 389-393. [CrossRef] [PubMed]

28. López, N.; Perez, E.; Tello, E.; Rodrigo, A.; Valentinuzzi, M.E. Statistical Validation for Clinical Measures: Repeatability and Agreement of Kinect ${ }^{\mathrm{TM}}$-Based Software. BioMed Res. Int. 2018, 2018, 6710595. [CrossRef]

29. Hawi, N.; Liodakis, E.; Musolli, D.; Suero, E.M.; Stübig, T.; Claassen, L.; Kleiner, C.; Krettek, C.; Ahlers, V.; Citak, M. Range of motion assessment of the shoulder and elbow joints using a motion sensing input device: A pilot study. Technol. Health Care 2014, 22, 289-295. [CrossRef]

30. Bonnechère, B.; Jansen, B.; Salvia, P.; Bouzahouene, H.; Omelina, L.; Moiseev, F.; Sholukha, V.; Cornelis, J.; Rooze, M.; Jan, S.V.S. Validity and reliability of the Kinect within functional assessment activities: Comparison with standard stereophotogrammetry. Gait Posture 2014, 39, 593-598. [CrossRef]

31. Hondori, H.M.; Khademi, M. A Review on Technical and Clinical Impact of Microsoft Kinect on Physical Therapy and Rehabilitation. J. Med. Eng. 2014, 2014, 1-16. [CrossRef]

32. Kizony, R.; Weiss, P.L.; Elion, O.; Harel, S.; Baum-Cohen, I.; Krasovsky, T.; Feldman, Y.; Shani, M. Development and validation of tele-health system for stroke rehabilitation. Int. J. Disabil. Hum. Dev. 2014, 13, 361-368. [CrossRef]

33. Wilson, J.D.; Khan-Perez, J.; Marley, D.; Buttress, S.; Walton, M.; Li, B.; Roy, B. Can shoulder range of movement be measured accurately using the Microsoft Kinect sensor plus Medical Interactive Recovery Assistant (MIRA) software? J. Shoulder Elb. Surg. 2017, 26, e382-e389. [CrossRef] [PubMed]

34. Çubukçu, B.; Yüzgeç, U.; Zileli, R.; Zileli, A. Reliability and validity analyzes of Kinect V2 based measurement system for shoulder motions. Med. Eng. Phys. 2019, 76, 20-31. [CrossRef] [PubMed]

35. Hwang, S.; Tsai, C.-Y.; Koontz, A.M. Feasibility study of using a Microsoft Kinect for virtual coaching of wheelchair transfer techniques. Biomed. Eng. 2017, 62, 307-313. [CrossRef] [PubMed]

36. Neto, J.S.D.C.; Filho, P.P.R.; Da Silva, G.P.F.; Olegario, N.B.D.C.; Duarte, J.B.F.; Albuquerque, V.H.C. Dynamic Evaluation and Treatment of the Movement Amplitude Using Kinect Sensor. IEEE Access 2018, 6, 17292-17305. [CrossRef]

37. Guneysu, A.; Siyli, R.D.; Salah, A.A. Auto-evaluation of motion imitation in a child-robot imitation game for upper arm rehabilitation. In Proceedings of the the 23rd IEEE International Symposium on Robot and Human Interactive Communication, Edinburgh, UK, 25-29 August 2014; pp. 199-204. 
38. Milgrom, R.; Otd, B.; Foreman, M.; Standeven, J.; Engsberg, J.; Morgan, K.A. Reliability and validity of the Microsoft Kinect for assessment of manual wheelchair propulsion. J. Rehabil. Res. Dev. 2016, 53, 901-918. [CrossRef]

39. Luinge, H.J.; Veltink, P.H. Measuring orientation of human body segments using miniature gyroscopes and accelerometers. Med. Biol. Eng. Comput. 2005, 43, 273-282. [CrossRef]

40. Renaudin, V.; Afzal, M.H.; Lachapelle, G. Complete Triaxis Magnetometer Calibration in the Magnetic Domain. J. Sens. 2010, 2010, 967245. [CrossRef]

41. Clark, R.A.; Pua, Y.-H.; Fortin, K.; Ritchie, C.; Webster, K.E.; Denehy, L.; Bryant, A.L. Validity of the Microsoft Kinect for assessment of postural control. Gait Posture 2012, 36, 372-377. [CrossRef]

42. Atrsaei, A.; Salarieh, H.; Alasty, A. Human Arm Motion Tracking by Orientation-Based Fusion of Inertial Sensors and Kinect Using Unscented Kalman Filter. J. Biomech. Eng. 2016, 138, 091005. [CrossRef]

43. Bo, A.P.L.; Hayashibe, M.; Poignet, P. Joint angle estimation in rehabilitation with inertial sensors and its integration with Kinect. In Proceedings of the 2011 Annual International Conference of the IEEE Engineering in Medicine and Biology Society, Boston, MA, USA, 30 August-3 September 2011; Institute of Electrical and Electronics Engineers (IEEE): New York, NY, USA, 2011; pp. 3479-3483.

44. Roy, G.; Bhuiya, A.; Mukherjee, A.; Bhaumik, S. Kinect Camera Based Gait Data Recording and Analysis for Assistive Robotics-An Alternative to Goniometer Based Measurement Technique. Procedia Comput. Sci. 2018, 133, 763-771. [CrossRef]

45. Cai, L.; Ma, Y.; Xiong, S.; Zhang, Y. Validity and Reliability of Upper Limb Functional Assessment Using the Microsoft Kinect V2 Sensor. Appl. Bionics Biomech. 2019, 2019, 7175240. [CrossRef] [PubMed]

46. Mangal, N.K.; Tiwari, A.K. Kinect v2 tracked Body Joint Smoothing for Kinematic Analysis in Musculoskeletal Disorders. In Proceedings of the 2020 42nd Annual International Conference of the IEEE Engineering in Medicine \& Biology Society (EMBC), Montreal, QC, Canada, 20-24 July 2020; pp. 5769-5772. [CrossRef]

47. HumanTrak Validation Case Study. Australian Catholic University Biomechanics Laboratory. Available online: https://www.valdperformance.com/wp-content/uploads/2018/12/HumanTrak-Validation-CaseStudy-ACU-Melbourne-2.0.pdf (accessed on 10 December 2018).

48. Yoon, T.-L. Validity and Reliability of an Inertial Measurement Unit-Based 3D Angular Measurement of Shoulder Joint Motion. J. Korean Phys. Ther. 2017, 29, 145-151. [CrossRef]

49. Lee, S.H.; Yoon, C.; Chung, S.G.; Kim, H.C.; Kwak, Y.; Park, H.-W.; Kim, K. Measurement of Shoulder Range of Motion in Patients with Adhesive Capsulitis Using a Kinect. PLoS ONE 2015, 10, e0129398. [CrossRef]

50. Schiefer, C.; Kraus, T.; Ellegast, R.; Ochsmann, E. A technical support tool for joint range of motion determination in functional diagnostics-An inter-rater study. J. Occup. Med. Toxicol. 2015, 10, 1-13. [CrossRef]

51. Poitras, I.; Dupuis, F.; Bielmann, M.; Campeau-Lecours, A.; Mercier, C.; Bouyer, L.J.; Roy, J.S. Validity and Reliability of Wearable Sensors for Joint Angle Estimation: A Systematic Review. Sensors 2019, 19, 1555. [CrossRef]

52. Puh, U.; Hoelhlein, B.; Deutsch, J.E. Validity and Reliability of the Kinect for Assessment of Standardized Transitional Movements and Balance: Systematic Review and Translation into Practice. Phys. Med. Rehabil. Clin. N. Am. 2019, 30, 399-422. [CrossRef]

53. Walmsley, C.P.; Williams, S.A.; Grisbrook, T.; Elliot, C.; Imms, C.; Campbell, A. Measurement of Upper Limb Range of Motion Using Wearable Sensors: A Systematic Review. Sports Med Open. 2018, 4, 53. [CrossRef]

54. Cools, A.M.; De Wilde, L.; Van Tongel, A.; Ceyssens, C.; Ryckewaert, R.; Cambier, D.C. Measuring shoulder external and internal rotation strength and range of motion: Comprehensive intra-rater and inter-rater reliability study of several testing protocols. J. Shoulder Elb. Surg. 2014, 23, 1454-1461. [CrossRef]

55. Mullaney, M.J.; McHugh, M.P.; Johnson, C.P.; Tyler, T.F. Reliability of shoulder range of motion comparing a goniometer to a digital level. Physiother. Theory Pract. 2010, 26, 327-333. [CrossRef]

56. Riddle, D.L.; Rothstein, J.M.; Lamb, R.L. Goniometric reliability in a clinical setting. Shoulder measurements. Phys. Ther. 1987, 67, 668-673. [CrossRef] [PubMed]

57. Hanney, W.J.; Kolber, M.J.; Marshall, J.S. The reliability of clinical measurements designed to quantify shoulder mobility. Phys. Ther. Rev. 2011, 16, 413-422. [CrossRef] 
58. Beshara, P.; Chen, J.; Lagadec, P.; Walsh, W.R. Test-Retest and Intra-rater Reliability of Using Inertial Sensors and Its Integration with Microsoft Kinect ${ }^{\mathrm{TM}}$ to Measure Shoulder Range-of-Motion. In Internet of Things Technologies for HealthCare; Lecture Notes of the Institute for Computer Sciences, Social Informatics and Telecommunications Engineering Series; Springer International Publishing: Cham, Switzerland, 2016; Volume 187. [CrossRef]

59. Jain, N.B.; Wilcox, R.; Katz, J.N.; Higgins, L.D. Clinical Examination of the Rotator Cuff. PM R. 2013, 5, 45-56. [CrossRef] [PubMed]

60. Koo, T.K.; Li, M.Y. A Guideline of Selecting and Reporting Intraclass Correlation Coefficients for Reliability Research. J. Chiropr. Med. 2016, 15, 155-163. [CrossRef] [PubMed]

61. Shrout, P.E.; Fleiss, J.L. Intraclass correlations: Uses in assessing rater reliability. Psychol. Bull. 1979, 86, 420-428. [CrossRef] [PubMed]

62. Weir, J.P. Quantifying Test-Retest Reliability Using the Intraclass Correlation Coefficient and the SEM. J. Strength Cond. Res. 2005, 19, 231-240. [CrossRef]

63. Portney, L.G.; Watkins, M.P. Foundations of Clinical Research: Applications to Practice, 3rd ed.; Pearson Prentice Hall: Upper Saddle River, NJ, USA, 2009; ISBN 978-0131716407.

64. Bland, J.M.; Altman, D. Statistical methods for assessing agreement between two methods of clinical measurement. Lancet 1986, 327, 307-310. [CrossRef]

65. De Winter, A.F.; Heemskerk, M.; Terwee, C.; Jans, M.P.; Devillé, W.; Van Schaardenburg, D.-J.; Scholten, R.J.P.M.; Bouter, L.M. Inter-observer reproducibility of measurements of range of motion in patients with shoulder pain using a digital inclinometer. BMC Musculoskelet. Disord. 2004, 5, 18. [CrossRef]

66. Terwee, C.; Bot, S.D.; De Boer, M.R.; Van Der Windt, D.A.; Knol, D.L.; Dekker, J.; Bouter, L.M.; De Vet, H.C. Quality criteria were proposed for measurement properties of health status questionnaires. J. Clin. Epidemiol. 2007, 60, 34-42. [CrossRef]

67. Anderson, D.B.; Mathieson, S.; Eyles, J.; Maher, C.G.; Van Gelder, J.M.; Tomkins-Lane, C.C.; Ammendolia, C.; Bella, V.; Ferreira, M.L.; Ammendiola, C. Measurement properties of walking outcome measures for neurogenic claudication: A systematic review and meta analysis. Spine J. 2019, 19, 1378-1396. [CrossRef]

68. Jordan, K.; Dziedzic, K.; Jones, P.W.; Ong, B.N.; Dawes, P.T. The reliability of the three-dimensional FASTRAK measurement system in measuring cervical spine and shoulder range of motion in healthy subjects. Rheumatology 2000, 39, 382-388. [CrossRef]

69. Springer, S.; Seligmann, G.Y. Validity of the Kinect for Gait Assessment: A Focused Review. Sensors 2016, 16, 194. [CrossRef]

Publisher's Note: MDPI stays neutral with regard to jurisdictional claims in published maps and institutional affiliations.

(C) 2020 by the authors. Licensee MDPI, Basel, Switzerland. This article is an open access article distributed under the terms and conditions of the Creative Commons Attribution (CC BY) license (http://creativecommons.org/licenses/by/4.0/). 